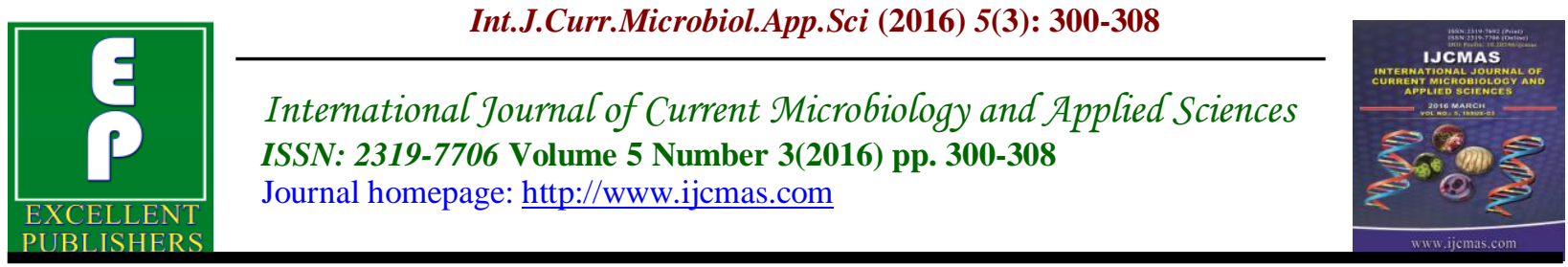

Original Research Article

http://dx.doi.org/10.20546/ijcmas.2016.503.036

\title{
Biological Activities of Different Parts of Saraca asoca an Endangered Valuable Medicinal Plant
}

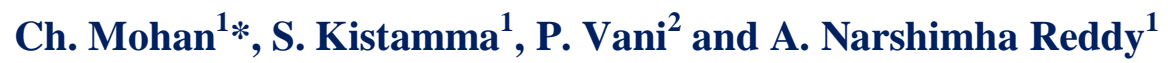 \\ ${ }^{1}$ Department of Botany, Osmania University, Hyderabad-500007, Telangana, India \\ ${ }^{2}$ Department of Botany, Raja Bahadur Venkata Rama Reddy Women's College, \\ Hyderabad, Telangana, India \\ *Corresponding author
}

\begin{abstract}
A B S T R A C T
Keywords

Saraca asoca,

Phytochemical screening, Antibacterial activity, Antioxidant activity, DPPH.

\section{Article Info}

Accepted:

15 February 2016 Available Online: 10, March 2016

This report describes the phytochemical relation of the antibacterial, antioxidant activity of different explants extract of Saraca asoca (Roxb.) De Wilde. In the present study preliminary phytochemical analysis of different extracts (bark, flower and leaves) was conducted, which revealed the presence of Alkaloids, Flavonoids, Glycosides, Saponins, Phenols, Steroids, Tannins and Triterpenoids. Quatitative estimation of Flavanoids and Phenols was conducted using methanolic, ethanolic and aqueous extracts. Screening for antibacterial activity of extracts of different $S$. asoca explants were performed against gram positive and gram negative bacteria by the disk diffusion method. The activities of the compounds were compared with standard strain for antibacterial properties of the imine base and its solvent extract evaluated and presenting in indicate that the compounds are active in exhibiting antibacterial role. Methanol bark extract showed maximum DPPH, radical scavenging activity which is the measure of antioxidant property at the concentration of above compounds at $200 \mu \mathrm{g} / \mu \mathrm{L}^{-1}$ follows the order Ascorbic acid > Bark extract of $S$. asoca while at higher concentration the same order is followed by bark extraction exchanged their position. There present study confirms of photochemical, antibacterial and antioxidant activity of all plant extract of $S$. asoca.
\end{abstract}

\section{Introduction}

Undoubtingly plants are a good source of biologically active natural products. While investigating the bioactive natural compounds, it is essential to have access to simple biological tests in order to locate required activities (Sener et al., 1994). This species is currently listed as a 'globally vulnerable' species by the IUCN 2013. (http://www.iucnredlist.org/apps/redlist/deta ils/34623/0).
Saraca asoca is a medicinally important and globally vulnerable plant species found in the evergreen forests of India (Thakur et al., 1989). India has often been referred to as the medicinal garden of the world and the medicinal plant Saraca asoca has been regarded as one of the foremost plants utilized from antiquity till date. Saraca asoca (Roxb.) De Wilde, is a small evergreen tree, belongs to the family 
Caesalpiniaceae is commonly known as Asoka, Sita Asoka and Haempushpam. It is an evergreen tree which is $9 \mathrm{~m}$ in height. The flowers are orange yellow in colour and arranged in dense corymbs. It occurs throughout India up to an altitude of $750 \mathrm{~m}$ in central and eastern Himalayas. Leaves are parpinnate $15-20 \mathrm{~cm}$ long and the leaflets 612 , oblong and rigidly sub-coriaceous. Leaves are narrowly lanceolate, cork like at the base and with a shot pestistipules are intra-petiolar and completely united. The bark is dark brown or grey or almost black with warty surface. Stem bark are rough and uneven due to the presence of rounded or projecting lenticles. Bark channeled, smooth with circular lenticles and traversely ridged, sometimes cracked. Fracture splinting exposing striated surface, a thin whitish and continuous layer is seen beneath the cork leaver. Flowers are fragrant. Flowers are Polygamous apetalous, yellowish orange turning to scarlet, in short laterally placed corymbose, auxillary panicles, bract small, deciduous and calyx petaloid. Seeds are 4-8, ellipsoid-oblong and compressed (Ali et al., 2008 and Jain et al., 1968).

Useful parts of the plant are barks, leaves, flowers and seed. The earliest chronicled mention of this tree is in the ayurvedic treatise and later in Charka Samhita (100 A.D.) in which Ashoka has been recommended in formulations for the management of gynecological disorders as anodynes. Ashokarista is a very famous formulation from the bark of this plant which is available commercially from various reputed companies and used to treat menstrual disorders. Different parts of Saraca asoca plant have been attributed with high medicinal value. Saraca asoca bark extracts are often used in Leucorrhea (Shukla et al., 2008). Flowers have shown encouraging anti-ulcer activity in albino rats (Maruthappan et al., 2010). Saracin, a lectin purified from Saraca indica seed integument, has been found to agglutinate human lymphocytes and erythrocytes irrespective of the blood group; it causes agglutination of Ehrlich ascites carcinoma (EAC) 3 cells as well as animal erythrocytes (Cibin et al., 2010).Moreover, chemopreventive activity of flavonoid fraction of Saraca asoca flower was reported in skin carcinogenesis (Ghosh et al., 1999). Larvicidal activity has also been recorded by using Saraca bark and leaves (Methew et al., 2008). Biochemical analyses have shown that leaves of $S$. asoca contain carbohydrates, proteins, glycosides, flavonoids, tannins and saponins (Pradhan et al., 2010). Different plant parts of S. asoca provide antibacterial (Nayak et al., 2011) CNS depressant, anti-pyretic, anthelmintic and analgesic activities (Nayak et al., 2010 and Varma et al., 2010).

All the plant parts are considered to contain medicinal properties. Leaves of Saraca asoca are known to contain carbohydrates, proteins, tannins and saponins and shows antibacterial activity (Pradhan et al., 2010). Barks and Flowers contain glycosides, steroids, saponins, carbohydrates and tannins (Pal et al., 1985). The flowers are also regarded as medicinally important plant part and used as therapeutic agent in treatment of diabetes, cancer and hemorrhagic dysentery, uterine infections as menorrhagia and other types of uterine disorders. It is also used in bleeding piles, bacillary dysentery.

Dried flower buds are reported to have antibacterial activity. Aqueous suspension of Saraca indica flower has antiulcer activity in albino rats (Maruthappan et al., 2010). Saraca asoca bark and flowers exhibit antitumour activity against DLA, S-180 and Ehrlich ascites carcinoma tumour cell lines, Larvicidal activity has also been recorded 
(Methew et al., 2008). Chemo preventive activity of flavonoid fraction of $S$. asoca is reported in skin carcinogenesis. During 'ashoka-sasthi' the flower buds are taken orally by women. Though phytoconstituents have been reported earlier in case of leaves and bark of the plant (Pradhan et al., 2010), no detail qualitative phytochemical analysis are found for flowers.

The antimicrobial activity of the stem and bark of Saraca indica have been evaluated against standard strain of Staphylococcus aureus, Escherichia coli, Salmonella typhimurium (Sainath et al., 2009). The leaves of Saraca indica also evaluated for anthelmintic activity (Nayak et al., 2011), analgesic and antipyretic activities (Pradhan et al., 2010), CNS depressant activity (Yadav et al., 2008). The reports of quantitative estimation of different antioxidants of the bark of Saraca asoca are hardly available. The antioxidant property is also related to the condition of soil and environment where the plant is grown. So in this investigation we are quantitatively estimate different phytochemicals such as total polyphenols, flavonoids, ascorbic acid and tannins and free radical scavenging activities of DPPH to evaluate antioxidants properties of the bark of Saraca asoca. In the Present study was phytochemical analysis, antibacterial activity and antioxidant study of the different parts of methanol extracts of Saraca asoca bark, flower and leaves was carried out.

\section{Materials and Methods}

Plant material used various plant parts (bark, flowers and leaves) of $S$. asoca were collected from the Botanical garden, Osmania University, Hyderabad. The collected plant materials were identified and voucher specimens were kept at the medicinal plant museum (Herbarium) of the Department of Botany.

\section{Preparation of Extracts}

Plant samples (bark, flowers and leaves) were washed with distilled water and airdried at room temperature for 7-10 days, then oven-dried at $40{ }^{0} \mathrm{C}$ to remove the residual moisture. The dried plant parts were pulverized and stored in air-tight containers at $4{ }^{0} \mathrm{C}$ for future use. $50 \mathrm{~g}$ of powdered samples of bark, flowers and leaves were extracted with methanol by soxhlation method at 60 to $80{ }^{0} \mathrm{C}$. The three filtrates were separately concentrated in water bath at $40{ }^{\circ} \mathrm{C}$ and evaporated under reduced pressure.

\section{Phytochemical Analysis}

The four extracts obtained from the powdered flowers of Saraca asoca were subjected to phytochemical tests to determine the presence of active secondary metabolites using standard procedures (Mohan et al., 2014).

\section{Antibacterial Activity}

The disc diffusion method was used to evaluate the antibacterial activity of the synthesized compounds against four bacterial strains viz; E. coli, P. aeruginosa, $K$. pnemone and $S$. aureus. Each organism was cultured in nutrient broth at $37{ }^{\circ} \mathrm{C}$ for 24 h. Then $1 \%$ broth culture containing approximately 106 colony forming units $(\mathrm{CFU} / \mathrm{mL})$ of test strain was added to nutrient agar medium at $45{ }^{\circ} \mathrm{C}$ and poured into sterile petri plates. The medium was allowed to solidify. $5 \mu \mathrm{L}$ of the test compound (40 mg/mL in DMSO) was poured on $4 \mathrm{~mm}$ sterile paper discs and placed on nutrient agar plates. In each plate standard antibacterial drug (ampicillin) and metal complexes were added. The plates were incubated at $37^{\circ} \mathrm{Cfor} 24 \mathrm{~h}$ and the antibacterial activity was determined by 
measuring the diameter of zones showing complete inhibition ( $\mathrm{mm}$ ) (Mohan et al., 2015).

\section{Radical Scavenging Activity}

The percentage of free radical scavenging activity is shown in Fig-2. This assay is based on decrease in absorbance value of DPPH at $517 \mathrm{~nm}$ on addition of complex. The experiment involves diluting the working solution of the plant extracts and the ascorbic acid standard (700, 600, 500, 400, 300 and $200 \mu \mathrm{g} / \mu \mathrm{L}-1)$ in methanol. DPPH concentration was kept constant (2 $\mathrm{mL}, 0.004 \%$ ). To this varying concentration of plant extracts and standard were added. The mixture was shaken vigorously and kept in dark for $30 \mathrm{~min}$ at room temperature. Then the absorbance was measured at 517 $\mathrm{nm}$ in a spectrophotometer. The whole experiment was carried out using spectroscopic grade methanol solvent at 298 $\mathrm{K}$. The radical scavenging activity has been measured by using the following Eq. 1 .

Suppression ratio $\left.(\%)=\left[\left(\mathrm{A}_{0}-\mathrm{A}_{\mathrm{i}}\right) / \mathrm{A}_{0}\right)\right] \mathrm{X} 100 \%$ (1)

Where $A_{i}=$ the absorbance in the presence of the ligand or its complexes, $\mathrm{A}_{0}=$ the absorbance in the absence of the ligand or its plant extracts.

\section{Results and Discussion}

\section{Phytochemical Analysis}

The present study contributes valuable information of bioactive compounds in $S$. asoca. Qualitative analysis of plant different extract (bark, flower and leaves) was carried out for Alkaloids, Flavonoids, Glycosides, Saponins, Phenols, Steroids, Tannins and Triterpenoids. Methanol, ethanol and aqueous extract of bark, flower and leaves has all the phytochemicals like flavonoids, glycosides, saponins, phenols, steroids, tannins and triterpenoids, except bark extract it has all phytochemical constituents except alkaloids, ethanol extract of flavoinoids and also glycosides and tannins are absent in aqueous extract of the bark. In flower extract it has all phytochemical constituents except alkaloids are absent in all extract, flavoinoids, glycosids and tannins are absent in aqueous extract and ethanol extract of the flower. In leaves extract it has all phytochemical constituents except alkaloids are absent in all extract, steroids are absent in methanolic extract, triterpinoids are absent in ethanolic extract and glycosides, tannins and phenols are absent in aqueous extract (Table-1). Which is similar to the reports of (Saha et al., 2012; Nayak et al., 2011). The plant bark, flower and leaves extracts were quantitatively analyzed for Flavonoids and Phenol (Table-2). Whereas, present our study reports of Steroids (Nayak et al., 2011). Indicated that Steroids were absent in $S$. asoca. Several medicinal properties have been attributed to Steroids (Ghatak et al., 2014 and Gayathri et al., 2013) but surprisingly, Steroids were found in the present study. Flavonoids and Phenol are however reported in the present study which agrees with the findings of (Ghatak et al., 2015).

\section{Anti-Bacterial Studies}

The antibacterial screening of the $S$. asoca different extracts (bark, flower and leaf) were performed against gram positive $(S$. aureus) and gram negative bacteria (E.coli, $P$. aeruginosa and $K$. pnemone) by the disk diffusion method. The activities of the compounds were compared with standard Ampicillin for antibacterial activity. The antibacterial properties of the imine base and its solvent extract evaluated and presenting in Fig-1, Table-3 and Graph-1,indicted that 
the compounds are active in exhibiting antibacterial role like bark $0.4,0.2,0.5$; flower $0.2,0.4,0.6$ and leaf $0.6,0.2,0.2$ in gram negative bacteria and bark 0.6, flower 0.4 , leaf 0.3 in gram positive bacteria. The order of activity towards gram negative bacteria is flower> bark> leaf and for gram positive bacteria the order is bark> flower> leaf. However reported in the present study which agrees with the findings of (Nayak et al., 2011; Sainth et al., 2009 and Sujatha et al., 2013).

Table.1 Table Shows Preliminary Phytochemical Screening of Methanol,

Ethanol and Aqueous Extract Saraca asoca

\begin{tabular}{|c|l|l|l|l|l|l|l|l|l|l|}
\hline \multirow{2}{*}{$\begin{array}{c}\text { S. } \\
\text { No }\end{array}$} & Phytoconstituents & \multicolumn{9}{|c|}{ Plant parts } \\
\cline { 3 - 10 } & & \multicolumn{4}{|c|}{ Bark } & \multicolumn{3}{|c|}{ Flower } & \multicolumn{3}{c|}{ Leaf } \\
\cline { 3 - 10 } & & $\begin{array}{c}\text { Met- } \\
\text { OH }\end{array}$ & $\begin{array}{c}\text { Et- } \\
\text { OH }\end{array}$ & Aqueous & Met- & Et- & Aqueous & Met- & Et- & Aqueous \\
OH & OH & & \\
\hline 1. & Alkaloids & $-v e$ & $-v e$ & $-v e$ & $-v e$ & $-v e$ & $-v e$ & $-v e$ & $-v e$ & $-v e$ \\
2. & Flavonoids & $+v e$ & $-v e$ & $+v e$ & $+v e$ & $-v e$ & $+v e$ & $+v e$ & $+v e$ & $+v e$ \\
3. & Glycosides & $+v e$ & $+v e$ & $-v e$ & $+v e$ & $+v e$ & $-v e$ & $+v e$ & $+v e$ & $-v e$ \\
4. & Saponins & $+v e$ & $+v e$ & $+v e$ & $+v e$ & $+v e$ & $+v e$ & $+v e$ & $+v e$ & $+v e$ \\
5. & Phenols & $+v e$ & $+v e$ & $+v e$ & $+v e$ & $+v e$ & $+v e$ & $+v e$ & $+v e$ & $+v e$ \\
6. & Steroids & $+v e$ & $+v e$ & $+v e$ & $+v e$ & $+v e$ & $+v e$ & $+v e$ & $+v e$ & $+v e$ \\
7. & Tannins & $+v e$ & $+v e$ & $-v e$ & $+v e$ & $+v e$ & $-v e$ & $+v e$ & $+v e$ & $-v e$ \\
8. & Triterpenoids & $+v e$ & $+v e$ & $+v e$ & $+v e$ & $+v e$ & $+v e$ & $+v e$ & $-v e$ & $+v e$ \\
\hline
\end{tabular}

Note:-Et-OH- Ethanol, Met-OH- Methanol and -ve-Absent, +ve-Present

Table.2 Quantitative Analysis of the Methonol Extracts of Saraca Asoca for Estimation of Flavonoids and Phenols

\begin{tabular}{|c|c|c|c|}
\hline S.No & Plant extract & Phytochemicals & $\begin{array}{c}\text { Average Estimated value } \\
(\mathbf{m g} / \text { gm })(\text { Mean } \pm \text { S.E })\end{array}$ \\
\hline \multirow{2}{*}{1.} & Flavonoids & Bark & $\mathbf{4 . 7 2} \pm \mathbf{0 . 7 4}$ \\
& & Flower & $5.22 \pm 0.15$ \\
& & Leaf & $5.86 \pm 0.54$ \\
\cline { 2 - 4 } 2. & Phenols & Bark & $115.98 \pm 0.67$ \\
& & Flower & $125.32 \pm 0.63$ \\
& & Leaf & $146.37 \pm 0.64$ \\
\hline
\end{tabular}

* Phenols are expressed as Gallic acid equivalent (GAE) and Flavonoids are expressed as Quercetin equivalents $(\mathrm{QE})$ in $\mathrm{mg} / \mathbf{1 0 0} \mathrm{gm}$

Table.3 Minimum Inhibition Zone (mm) Complexes $(\mu \mathrm{g} / \mathrm{ml})$

\begin{tabular}{|l|c|c|c|c|}
\hline \multirow{2}{*}{ Compound } & \multicolumn{3}{|c|}{ Bacterial inhibition zone (mm) Gram (+) } & $\begin{array}{l}\text { Bacterial inhibition zone } \\
(\mathbf{m m}) \text { Gram (-) }\end{array}$ \\
\cline { 2 - 5 } & E. coli & P. aeruginosa & K. pnemone & S. aureus \\
\hline 1. Bark & 0.4 & 0.2 & 0.5 & 0.6 \\
\hline 2. Flower & 0.2 & 0.4 & 0.6 & 0.4 \\
\hline 3. Leaf & 0.6 & 0.2 & 0.2 & 0.3 \\
\hline
\end{tabular}


Fig.1 Antimicrobial Activity of Bark, Flower and Leaves Extract of S. asoca (a) E.coli, (b) P. aeruginosa, (c) K. pneumoniae (Gram Negative) and (d) S. aureus (Gram Positive) Ampicillin as Positive Control

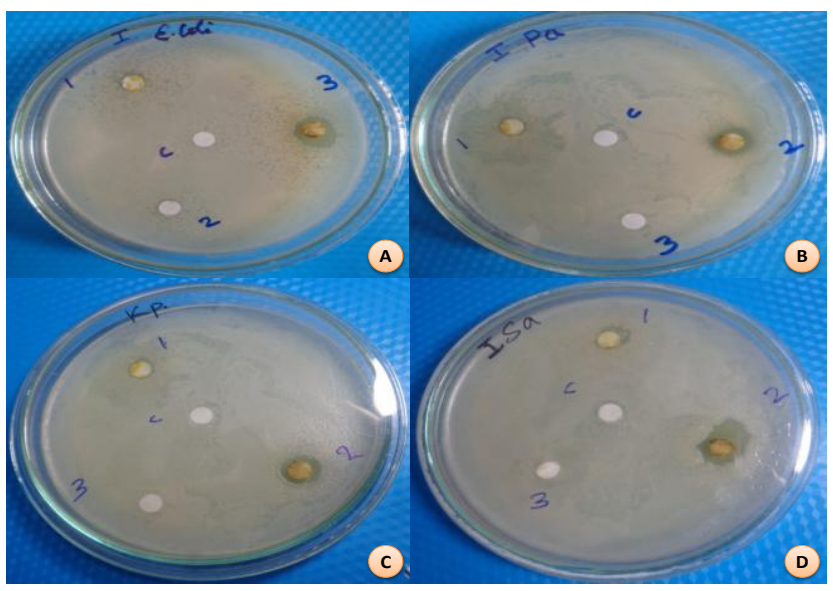

Fig.2 Radical-Scavenging Activity of the Bark Extract of S. asoca on DPPH Radicals (\%)

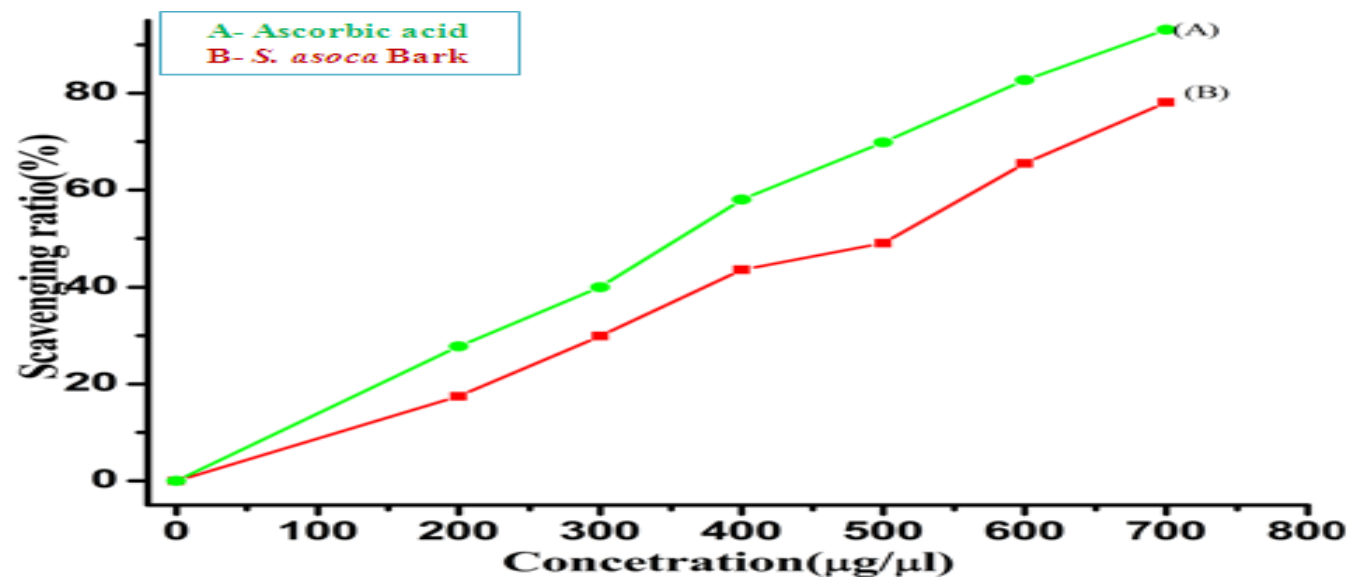

Graph.1 Minimum Inhibition Zone (mm) Complexes $(\mu \mathrm{g} / \mathrm{ml})$

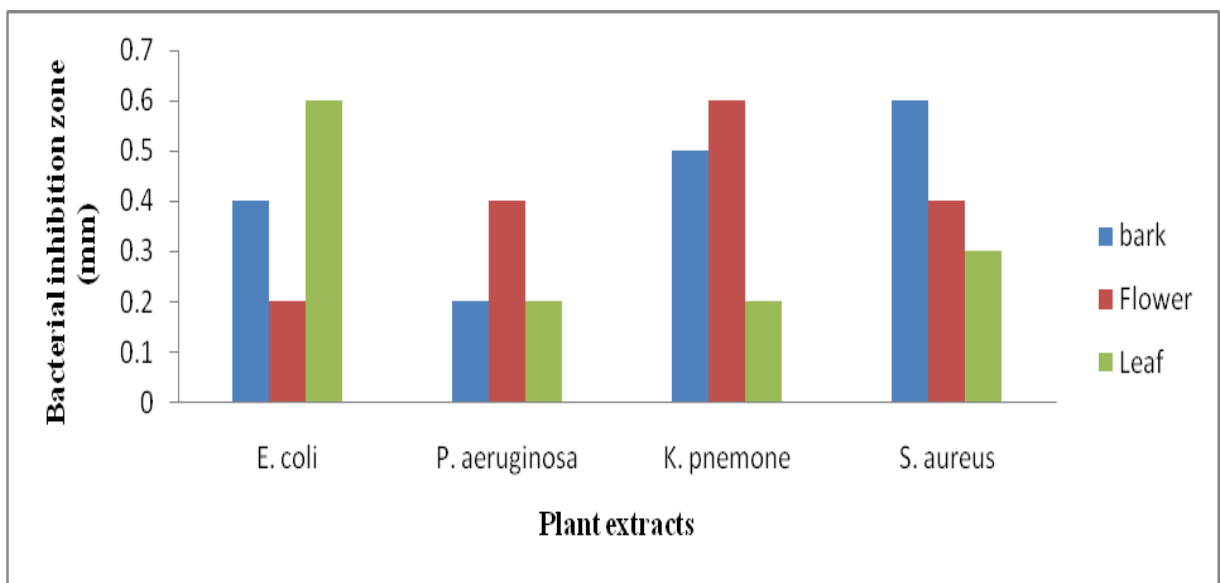




\section{Antioxident Properties}

The model of scavenging the stable DPPH radical is a widely used technique to screen antioxidant properties by spectrophotometer in a very short time period. When the reaction between antioxidant molecule and DPPH radical occurs, it results in decrease in absorbance at $517 \mathrm{~nm}$. This is because the radical is scavenged by antioxidants through donation of hydrogen to form the reduced form (DPPH-H), and this property is also visually noticeable as the color changes from purple to yellow. The more rapidly the absorbance decreases, the more potent is the antioxidant compound. In the present study the antioxidant activity of bark extract of $S$. asoca was evaluated by scavenging stable DPPH radical (Fig:-2). The DPPH radical scavenging activities were found to be 28.16 $\%$ for ascorbic acid, $16.86 \%$ for bark extract (B), at concentration of the $200 \mu \mathrm{g} / \mu \mathrm{L}^{-1}$. Ascorbic acid exhibited higher DPPH scavenging activity than the compound at all concentrations. At the concentration of 700 $\mu \mathrm{g} / \mu \mathrm{L}^{-1}$ scavenging activities were found to be 95.08 and $78.12 \%$ for Ascorbic acid and bark extract of S.asoca respectively. The metal scavenging activity which is the measure of antioxidant property at the concentration of above compounds at 200 $\mu \mathrm{g} / \mu \mathrm{L}^{-1}$ follows the order: Ascorbic acid > Bark extract of $S$. asoca while at higher concentration the same order is followed by bark extraction exchanged their position.However reported in the present study which agrees are similar with their antioxidative potential (Ghatak et al., 2015; Panchawat et al., 2010).

In conclusion, the Present study involving preliminary phytochemical studies of different extract (bark, flower and leaves) revealed the presence of all secondary metabolites different extract and some compounds were also estimated quantitatively (Flavonoids and Phenols), methanol extraction is proved to be the best solvent system for the all parts $S$. asoca. Study confirms the antibacterial activity of bark, flower and leaf extract of $S$. asoca the extract found effective bacterial strain, the order of activity towards flower antibacterial activity higher then bark and leaf in gram negative bacteria, where as bark activity is more when compare to flower and leaf in gram positive bacteria. The antioxidant activity evaluated for the methanolic bark extraction of $S$. asoca has excellent compound activity to eliminate the hydroxyl radicals. These observations can lead to the development of new potent antioxidants. This is valuable information for preparation of drugs in pharmaceutical industry and stress the need for more intensive research since they play a great role in healthcare.

\section{Acknowledgment}

We are thankful to Department of Botany, Osmania University, Hyderabad for lab facilities and valuable suggestions and financial assistance is gratefully acknowledged.

\section{References}

Ali, M. 2008. Pharmacognosy. CBS Publishers \& Distributors, New Delhi. 668-669.

Arindam, Ghatak, Sidhesh Nair, Ambrish Vajpayee, Palak Chaturvedi, Shardool Samant, Ketki Soley, Subhash Kudale, Neetin Desai. 2015. Evaluation of antioxidant activity, total phenolic content, total flavonoids, and LC-MS characterization of Saraca asoca (Roxb.) De. Wilde. Int. J. Adv. Res., Volume 3, Issue 5: 318-327.

Cibin, T.R., Gayathri, D.D, Abraham, A. 2010. Chemoprevention of skin 
cancer by the flavonoid fraction of Saraca asoca. Phytother. Res., 24: 666-672.

Gayathri, P, Jeyanthi, G.P. 2013. Radical scavenging activity of Saraca indica bark extracts and its inhibitory effect on the enzymes of carbohydrate metabolism. Int. J. Chemical. Pharm. Sci., 4: 87-96.

Ghatak, A.A., Chaturvedi, P.A., Desai, N.S. 2014. Indian Grape Wines: A Potential Source of Phenols, Polyphenols, and Antioxidants. Int. J. Food. Prop., 17: 818-828.

Ghosh, S., Majumder, M., Majumder, S., Ganguly, N.K., Chatterjee, B.P. 1999. Saracin: a lectin from Saraca indica seed integument induces apoptosis in human T-lymphocytes. Arch. Biochem. Biophys., 371: 163168.

Jain, S.K. 1968. Medicinal Plants. National Book Trust, New Delhi, 1968: 124.

Maruthappan, V., Shree, K.S. 2010. Antiulcer activity of aqueous suspension of Saraca indica flower against gastric ulcers in albino rats. J. Pharmaceutical Res., 3(1): 17-20.

Mathew, N., Anitha, M.G., Bala, T.S.L., Sivakumar, S.M., Narmadha, R., Kalyana sundaram, M. 2008. Larvicidal activity of Saraca indica, Nyctanthes arbor-tristis, and Clitoria ternatea extracts against three mosquito vector species. Parasitol Res., 104: 1017-1025.

Mohan, Ch., Rama devi, B., Manjula, P., Prathibha Devi, B. 2014. Phytochemical investigations and micropropagation of Tylophora indica (burm. F.) Merill from nodal explants. J. Ind. Bot. Soc., 93(1\&2): 42-49.

Mohan, Ch., Sridhar, S., Mohan, B., Krishnaveni, S.B., Karnakar Reddy, S. 2015. Antibacterial activity and phytochemical screening of Hemidesmus indicus L. B. BR. Int. J. Pure App. Biosci., 3(2): 221225.

Nayak, S., Sahoo, A.M., Chakraborti, C.K and Haque, M.N. 2011. Antibacterial activity study of Saraca indica leaves extract. IJPRD., 3(3): 160163.

Pal, S.C., Maiti, A.P., Chatterjee, B.P., Nandy, A. 1985. Antibacterial activity of flower and flower buds of Saraca indica. Ind. J. Med Res., 82(2): 188-189.

Panchawat, S., Sisodia, S.S. 2010. In vitro antioxidant activity of saraca asoca roxb. De wilde stem bark extracts from various extraction processes. Asian J. Pharm. Clin. Res., 3: 3.

Pradhan, P., Joseph, L., George, M., Kaushik, N., Chulet, R. 2010. Pharmacognostic Phytochemical \& Quantitative Investigation of Saraca asoca leaves. J. Pharm. Res., 3(1): 776-780.

Pradhan, P., Joseph, L., George, M., Kaushik, N., Chulet, R. 2011. Pharmacognostic, phytochemical \& quantitative investigation of Saraca asoca leaves. J. Pharm. Res., 3(4): 776-780.

Sainath, R., Prathiba, J., Malathi, R. 2009. Antimicrobial activity of the stem bark of Saraca indica. Euro. Rev. Med. Pharmacol. Sci., 13: 371-374.

Sener, B. 1994. Recent results in the search for bioactive compounds from Turkish medicinal plants. Pure Appli. Chem., 66: 2295-2298.

Shukla, R., Chakravarty, M., Gautam, M.P. 2008. Indigenous medicine used for treatment of gynecological disorders by tribal of Chhattisgarh, India. $J$. Med. Pl. Res., 2(12): 356-360.

Sujatha, S., Gowri Prakash. 2013. Bioactive screening and antimicrobial activity 
of flowers from the selected three medicinal plants on chosen microbes. Int. J. Curr. Microbiol. App. Sci., 2(5): 211-221.

Thakur, R.S., Puri, H.S., Hasain, A. 1989. Major medicinal plants of India, Lucknow, Central Insitute of Medicinal and Aromatic Plants. pp. 208-211.

Varaprasad, N., Suresh, A., Suresh, V. 2011. Anti pyretic activity of methanolic extract of Saraca asoca (roxb.) De
Wild leaves. IJPRD, 3: 202-207. Verma, A., Jana, G.K., Sen, S., Chakraborty, R., Sachan, S., Mishra, A. 2010. Pharmacological evaluation of Saraca indica leaves for central nervous system depressant activity in mice. J. Pharm. Sci. Res., 2(6): 338343.

Yadav, A.V., Kawale, L.A., Nade, V.S. 2008. Effect of MorusalbaL. (mulberry) leaves on anxiety in mice. Ind. J. Pharmacol., 40: 32-36.

\section{How to cite this article:}

Mohan, Ch., Kistamma, S., Vani, P., Narshimha Reddy, A.2016. Biological Activities of Different Parts of Saraca asoca an Endangered Valuable Medicinal Plant. Int.J.Curr.Microbiol.App.Sci. 5(3): 300-308. doi: http://dx.doi.org/10.20546/ijcmas.2016.503.036 